attention to another part of the address, because the opinion of the speaker coincides with that which we have frequently expressed. Lord Shaftesbury attributes the moral as well as the physical mischiefs which beset the lowest class to the wretched state of the dwellings in which they live. That typhus and cholera, and general permanent debility, should be caused by a narrow and undrained lodging is obvious enough, but it is not every one that perceives how drunkenness, profligacy, and general moral degradation, are directly the consequences of choked rooms, filthy smells, and the want of the appliances of cleanliness. That such is the case, however, is beyond a doubt. The craving for gin is the almost inevitalle result of living in a vitiated atmosphere, and long experience has convinced the most persevering schoolmasters that it is almost impossible to educate children who inhabit the worst kind of courts. Here are certainly facts, not only for the Social Science Association, but for Parliament, and they all seem to point one way-that is, in the direction of more efficient State control. The most stalwart partisans of laissez faire must be shaken in their creed when they consider these things. It may be that we shall have to approach to Continental usages in many of these matters. How far, and by what machinery, are questions which the Social Science people might well consider.-The Times, October 6th.

\title{
Psychological Experts.
}

Ir is the fashion to say that medical men in general are not good witnesses. The recent case of Hunter $v$. Sharpe, at least, lends no support to such a theory. The medical evidence for the defence was admirably given; where all were good it would seem invidious to mention names, but Dr. Williams's evidence was especially noticeable. The masterly way in which the questions of counsel were met, and the clearness and force with which the points were brought forward, reflect much credit upon the scientific witnesses engaged. If psychological experts were as careful and as exact we should not so often see the contempt of juries for their opinion, exhibited by verdicts opposed to their evidence. We hope to have seen the last of "sensation" lunacy trials; should one again arise, let the experts imitate in their manner of giving evidence the careful precision, the calm, unbiassed manner, and the knowledge of the subject,' shown by the medical witnesses in the late cause.-The Lancet, December 8th.

\section{Lunatics at Home.}

If the Commissioners of Lunacy should be induced to supplement the asylum system of England by the farming lunatics in private dwellingsand the deficiency of existing accommodation has been so murked for some time that we have before been induced to recommend that course-one thing must necessarily and inmediately follow - a great addition to the inspecting power of the board. At present lunatics in dwellings are practically uninspected in England; that is to say, they are not inspected more than once a year, and if in the house of a relative not at all. Chancery lunatics only are, under such circumstances, inspected four times annually. It is the characteristic danger of the cottage and private house system, that it lends itself very readily to abuse. The history of Scottish lunatics showed this very fully ; and, until lately, the grossest abuses existed where lunatics were confined in private dwellings in that country. A more perfect system of 